\title{
Communication
}

\section{Practice-Based Interdisciplinary Approach and Environmental Research}

\author{
Ranjan Kumar Datta \\ College of Education, University of Saskatchewan, 28 Campus Drive, Saskatoon, SK S7N 0X1, Canada; \\ ranjan.datta@usask.ca; Tel.: +1-306-966-1736 \\ Academic Editor: Yu-Pin Lin \\ Received: 6 October 2016; Accepted: 3 March 2017; Published: 7 March 2017
}

\begin{abstract}
Interdisciplinary researchers and educators, as community members, creators of knowledge, and environmental activists and practitioners, have a responsibility to build a bridge between community practice, academic scholarship, and professional contributions aimed at establishing environmental sustainability. In this paper, I focus on an undervalued area of environmental politics, practices, and often unarticulated assumptions which underlie human-environmental relations. This article challenges interdisciplinary studies that are not connected with practice by reconfiguring the meaning of a community-based, interdisciplinary approach. Drawing from works by Foucault, Latour, and Haraway, this paper first shows how to reconfigure the meaning of an interdisciplinary approach. Second, using Bourdieu and Brightman's ethnographic studies as a framework, the paper situates practice as central to our efforts to deconstruct and replace current interdisciplinary initiatives with a practice-based approach. Through a practice-based interdisciplinary approach (PIA), environmental educators and researchers gain an awareness of and learn to make an investment in sustainable communities. As teams of environmental researchers practising in the local community, they are meaningfully involved with the community, with each other, and with the environment.
\end{abstract}

Keywords: interdisciplinary practice-based approach; scientific research; Foucault; Haraway; Latour; Bourdieu; Brightman

\section{Introduction}

Efforts to better link theoretical understanding with people and their practice involved in community-based environmental research are receiving increased interest and attention. Focused research on the intersections between scientific environment research and society's practice has provided substantial insight into community-based dynamics of large-scale environmental research and the related impacts on people, animals, natural resources, and ecosystems, yet our ability to connect this research to reality remains limited. Although a practice-based approach is able to address these complex environmental problems by facilitating collaboration between scientists and environmental resource management decision-makers, there are very few environmental researchers engaged in this kind of collaborative work [1]. Researchers in environmental research have emphasised the issue of science research and people's ways of doing; however, the concept of practice-based approach in environmental research is undefined and poorly researched. A need exists for theoretical and empirical studies of environment. Focusing on practice-based interdisciplinary approach (PIA), this paper explores a long-standing theoretical and empirical concern of what works, where, when, and why. Special attention is given to community's practice: how do community people deal with environmental matters, and in what ways do they interact, communicate, understand, evaluate, and manage the connections between their everyday needs and practices on the one hand, and scientific environmental research on the other? 
The concept of a practice-based approach can challenge our scientific static mindset regarding who we are as environmental researchers and educators [2,3]. A number of environmental studies argue that researchers are limited within science research and/or do not develop ideas and ways of doing "from within", from the people, yet [3-6]. The scientific research is often insufficient to deal with the full complexity of the interplay of variables in environmental research [4,5]. Only scientific forms of thinking and doing does not connect people's interactions, local knowledge, and local values, which form an integral part of the contexts of everyday practice [6,7]. Therefore, in environmental research, interconnection between people's practice and science research is vague and underexplored, and yet to be conceptualised. The practice-based approach is thus concerned with the nature of practice within a local community and leads to new knowledge that has operational significance for that practice [1]. Such an approach not only minimises our static mindset about scientific research/practice boundaries, but also includes practice as an integral part of its method, and often falls within the general area of participatory, community-driven action research, intended to provide outcomes that benefit potential audiences. We as educators or researchers, have a responsibility to explore how scientific "thought traditions, hitherto heavily dependent on the dualism of nature and society" [8], (p. 11) in our interdisciplinary environmental research [9]. Consequently, working towards PIA is crucial for environmental research and for society in general [1-5]. Thus, this paper presents a concept analysis of a practice-based approach and its implications for interdisciplinary environmental research.

A PIA is required to tackle the challenges in environmental research. For redeveloping environmental in research from PIA, I have divided this paper into the following sections: first, a critical discussion of some of the significant challenges in scientific interdisciplinary research (SIA); second, PIA is defined, including its scientific and social relevance, and what we accomplish when we redefine environmental research from PIA; third, I discuss how to redefine environmental research by using three concepts (Foucault's concept of heterotopia, Latour's concept of thing, and Haraway's cyborg); fourth, a discussion of why we need to move from the scientific interdisciplinary approach to a practice-based interdisciplinary approach based on Bourdieu's and Brightman's ethnographic studies; and fifth, an explanation of why we need to advocate for new ways of understanding and discover the meaning of scientific environmental research and society for their potential advancement. I conclude with an argument that PIA can impact future environmental research and researchers, and encourage community practice within a critical academic framework.

\section{Challenges with Scientific Interdisciplinary Approach (SIA) in Environmental Research}

While the importance of a SIA has been widely recognised in environmental research, it is still very much concentrated within specific disciplinary areas, and the integration of interdisciplinary studies has become unusual in traditional fields of study $[10,11]$. Despite some successes in educating the different disciplines to work collaboratively, the degree of SIA at present is insufficient and sporadic $[6,12]$. There are a number of common challenges associated with SIA. Some of the significant challenges include: structural constraints, conceptual barriers, language and communication barriers, and challenges in scientific scholarly research trainings.

The structural constraints are one of the significant limitations for SIA. Studies [10-13] claim that the interconnection between different disciplines is one of the major challenges for SIA. For example, in the late 1950s, Thomas Kuhn presented an analysis of what he called "the essential tension between tradition and innovation", focusing, in the long run, on the issue of practice [14]. His work provides the direction for interdisciplinary research to solve the many complex problems that face us in today's society; however, the uneven implementation of many disciplinary scientists has made interdisciplinary studies a weak domain. Current tendencies of an interdisciplinary approach in the sciences and/or social sciences do not live up to Kuhn's dreams of disciplinary collaborations or problem-oriented issues. Kuhn's interdisciplinary forms of research involve collaboration on real-life issues/problems [14]. These forms of collaboration are generally capable of understanding the reason for and value of adopting particular propositions. Without a focus on problems or everyday practice, 
SIA would never be initiated and, instead, monodisciplinary communities of highly specialised experts would remain isolated, unable to work on problems whose solutions transcend disciplinary boundaries. I agree with Kuhn that SIA cannot overcome structural constraints through old or new disciplinary tools unless it has a practice-based focus on solving problems [14-17].

The conceptual contradictions present an important challenge in SIA. Despite increasing emphasis on SIA, the last 20 years have illustrated that integrating research disciplines to deal with complex nature/culture-related problems is far from unproblematic. For example, Sievanen et al. (2012) explain that conceptual barriers play a significant role in SIA, and they are raised from different perspectives: (i) researcher's personal characteristics; (ii) the socio-institutional context within which the researcher acts, and (iii) the institutional system upon which the researcher is acting [15]. Sievanen et al. (2012) explain conceptual barriers in SIA as: the different perspectives on conservation held by social and natural scientists; expectations by natural scientists about the results of social science research; a tendency by natural scientists to see social scientists primarily as educators, people who can remove political obstacles to change, or community facilitators, and outreach coordinators (as opposed to scholarly researchers); the social context in which biophysical science has developed (with humans seen as separate from nature); power dynamics in interdisciplinary teams; and a lack of shared understanding about what is meant by including humans [15], (p. 2). According to Sievanen et al., SIA is not only more connected with institutional policies and purpose than practice or problem, but is also rooted in the institutional, political, and cultural contexts in which the projects are being implemented [14]. Similarly, Stock and Burton (2011) suggest that the conceptual ambiguities within SIA researchers are a fundamental reason for the failure of integrated, practice-based research projects [15]. The lack of practice-based research can create many ambiguities, such as: the basic lack of interdisciplinary infrastructure (e.g., lack of researchers trained in integrated research); the lack of a philosophical stance or epistemological and ontological incompatibilities; and the researcher's political stand on a particular research issue [1].

SIA's limitations in language and communication have often been cited as significant barriers to environmental research. These hindrances are often informed by unannounced assumptions and affect project outcomes. It is the rare scholar who seeks to read outside his own discipline in search of new information and new metaphors that can increase the precision and comparability of their work [16]. Wainwright (2010) makes a similar observation related to the discipline of geography's involvement in climate change research - this is a domain where climate scientists advocate social changes without engaging with practice [17].

Faculty and graduate students pursuing interdisciplinary problem-solving approaches often find themselves in departments or schools dominated by conventional disciplinary or multidisciplinary administrators and colleagues, a fact that presents career management challenges, insecurities, and personal and professional anxieties [18]. There is a strong possibility that disciplinary-dominated SIA will lead to inflexibility and practice-less, theoretically based assumptions. A contextual understanding and analytical clarity is required to solve these problems so that students can manage their careers, as demonstrated by the different SIA challenges I faced in my PhD research training.

In addition to the above challenges, scientific scholarly training was one of the important challenges for my understanding and working on environmental research. As an environmental student, educator, and researcher, I have spent more than 15 years investigating the concept of environmental research. I was curious to know why environmental research in SIA is a contradictory and confused concept in environmental sustainability studies. We (my department colleagues and I) have had various debates in attempting to define SIA, including classroom discussions, group activities, Indigenous story-sharing circles, community gardening activities, weekly seminar talks, artwork, music, dance, and harvesting. For example, in our interdisciplinary school's weekly seminars, we had different groups of people from different disciplines, including professionals and activists, who attempted to define the meanings of SIA for us ( $\mathrm{PhD}$ and Masters students). Attempting to interconnect their views of SIA was very confusing. Most of the definitions were narrowly defined 
based on a disciplinary approach or profession. These separate approaches often came up in our seminar discussions; however, they were disconnected from participants' everyday activities. Both discipline-oriented and profession-oriented SIA practitioners were busy explaining how they could create a more effective interdisciplinary approach. In this interdisciplinary $\mathrm{PhD}$ program, we felt that, in most cases, disciplinary and professional practices dominated; the local problems or issues, people and their community's practice became secondary. Within these limitations, we often discussed unanswered questions: Why are we studying SIA if we cannot challenge disciplinary problems? What can we do if we cannot overcome disciplinary and professional practices? Is SIA simply a strategy for providing a license or certificate that will make a profit for universities or corporate companies?

My cross-cultural education, socialisation, and research with Indigenous and non-Indigenous communities guided my thoughts, inspired me to think differently, and challenged my Western scientific research training and education. My research into Foucault, Haraway, and Latour's contributions motivated me to think differently and to formulate an interdisciplinary approach that speaks for local people, issues, traditions, culture, and needs. I questioned how far we could progress if we were unable to create SIA from our everyday practices $[13,19,20]$.

\section{What Is PIA and Why Is It Scientifically and Socially Relevant?}

Within environmental research, the concept of PIA has served as key in efforts to move beyond problematic dualisms in science and society, including those of object and subject, actor and actions, practice and knowledge, mind and body, and nature and culture. First-hand ethnographic observation and historical documents left me pondering the following points: What is PIA? Why do we need to employ PIA in our everyday life? Why do we need to create new forms of PIA that are diverse, fluid, positive and hopeful? What do we accomplish when we redefine PIA? These are the questions that guided my interest in moving from SIA to a PIA.

\subsection{What Is PIA in Environmental Research?}

Practice-based approach advocate Reckwitz (2002) has identified PIA as subset of culture, and that it is interconnected with our social values [1]. He explained practice-based approach through two separated concepts: practice (praxis) and practices (praktiken). The practice (praxis) is "whole of human action", which is connected with reality, not only thinking [1], (p. 249). On the other hand, practices (praktiken) are forms of thinking that come from culture, emotion, and others. A practice is "thus a routinized way in which bodies are moved, objects are handled, subjects are treated, things are described and the world is understood. This way of understanding is largely implicit" [1], (p. 249). Reckwitz discusses that a practice- " "a way of cooking, of consuming, of working, ... etc.—-forms so to speak a "block" whose existence necessarily depends on the existence and specific interconnectedness of these elements, and which cannot be reduced to any one of these single elements" [1], (p. 250). Such a definition allows for a multi-relational understanding of practices as performed and produced activities in real life. Practices, such as cultivating, cooking, eating transporting, working, and parenting, are-in this and other central definitions in practice theory-seen as coordinated activities. Through practice-based approach, Reckwitz breaks the boundaries between science and society or nature and culture. All doings and sayings are parts of a practice. Sociologist Giddens (1984) explains that practices are the basic unit of social research [21,22]. Similarly, Indigenous scholar Wilson (2008) explains practice is a form of relationships. According to Wilson, our relationships determine our practice, and our practice determines our culture. Practice is interconnected with culture, and cannot/should not be separated [23-25].

The environmental research in PIA, thus, is a multidimensional framework which centres community, promotes an interdisciplinary learning process, and reflects an experiential learning process. Community is at the centre of the practice. Understanding community's perspectives on science, social, cultural, economic, and environmental issues is core for this PIA. Learners in this environment are exposed to their personal notions of community, which assists them in evaluating 
multiple and competing concepts of community. This process helps in bridging the gap between science and society. Community engagement is one of the foundations of PIA. It is through community engagement that environmental researchers, scholars, and students learn to appreciate the experiences that impact not only the environment, but also the individuals and communities as they interact with the environment. Rather than entering the community as experts, educators and researchers need to enter as learners as well as educators in the spirit of sharing expertise. Effective environmental research principles require the input of those who know the physical environment the best, and those who are most impacted by the decisions made about the community [26]. Thus, the term PIA has become so watered down that it can be anything from code for involving local people to a disciplinary imperative. Increasingly, research is moving towards more practice and/or problem-oriented endeavours. Effective interconnection between science research and culture in different disciplines is necessary to maximise the potential benefits of PIA for future research activity.

\subsection{Why Is PIA Scientifically and Socially Relevant?}

It is becoming increasingly clear why PIA is becoming more important in environmental research. The SIA has not only failed to overcome our traditional perspectives on conceptual contradictions, but has also created many difficulties for practitioners-those who are looking for research-based advice on the principles and practices of environmental research. Reconfiguring the meaning of environmental research from a practice-based approach is important for environmental educators seeking to identify a body of justified judgements regarding learning about environmental research that can guide their work. Today, the impact of the work of Foucault, Latour, and Haraway is widely evident in overcoming nature/culture boundaries [12-15]. However, fewer studies have taken the lead to develop a bridge between the contributions of Foucault, Latour, and Haraway. The substantial contributions of these post-structural scholars can play a significant role in breaking down nature/culture misconceptions in our research and leading towards PIA [13]. Such practice-based approach promotes building bridges between formal and practice-based ways of thinking and acting. The scholarship of Foucault, Latour, and Haraway present a substantial challenge to nature/culture illusions and build a collective form of practice-based interdisciplinary approach (PIA) [13]. According to Law (2004), this collective form of PIA will allow us to proceed to the transformation of the venerable distinction between facts and values [25]. This form of PIA will build collective common knowledge that will answer the question "Can we live together?" [24], (p. 8). In Archaeology of Knowledge (2004), Foucault links the question of nature to various historical practices, while Latour, in Politics of Nature (2004), sheds light on the production of knowledge with his explorations of non-human participation in our collective life [25-27]. Haraway similarly argues that, "The idea that nature is constructed, not discovered, that truth is made, not found, is the keynote of recent scholarships in the history of science" [9] (p. i). On a similar point, another post-structural scholar, Law (2004), suggests that combining Haraway's and Latour's epistemologies is an emergent step in moving away from the nature/culture fallacy $[25,26]$.

There is a serious limitation in current SIA to environmental education and research and, more notably, appropriate and effective PIA for assessing professionals', researchers', and educators' knowledge of environmental research [11]. By integrating academic training and practice, PIA fosters efforts to implement a practice-based approach and suggests strategies to accelerate the translation of a practice-oriented focus across disciplines [1]. Escobar (1999) and Whatmore (2006) see practice in environmental research as neither singular nor static; rather, they see it as diverse, complex, and anti-essential [9,26-30]. It is collaboration from and within people's interaction in which practitioners and participants bring their multiple relevant disciplines to bear on phenomena that transcend the range of traditional disciplines [30]. A participant's community is at the core of PIA, reflecting both an interdisciplinary orientation and experiential education. Through community engagement, PIA prepares practitioners for the use of multiple lenses to assess, engage, and remediate the issues they confront. Learners explore how the environment influences the community and how the community responds. Students are introduced to methodologies that encourage their respect for 
the wisdom of community members and are encouraged to work with community partners on critical problems. The transfer of knowledge between the community and the student (as a representative of the university) makes research more socially relevant and fit for use in society [31]. In this paper, I suggest that PIA is a community-engaged, interdisciplinary, and integrated approach, bringing together the social, technological, and scientific fields of practice, and providing a setting for creative investigation and response [8].

\subsection{What Do We Accomplish When We Redefine PIA?}

Moving forward from SIA to PIA, I argue that Foucault, Latour, and Haraway's contributions are not only useful in deconstructing the science/society misconceptions but are also significant in reconstructing our collaborative ways of understanding environmental research. However, while they are successful enough in recreating collaboration, their significant contributions are not enough to challenge today's ecological nature/culture epistemology until we can connect it with everyday practice. Local knowledge, such as local customs in examining nature [29], are often left out. Therefore, Escobar (1999) argues that although Foucault, Latour, and Haraway's contributions in science and social science studies have made significant shifts from colonial to postcolonial, structural to post-structural, and modern to postmodern, they may not have been successful enough to remove themselves from Western scientific illusions [9]. For instance, Nadasy (1999) and Escobar (2010) argue that Western scientific knowledge systems take for granted the existing power relations between local people and the state by assuming that local knowledge is inappropriate, inadequate, outdated, and useless in existing knowledge-making processes [32,33]. Therefore, in connecting with everyday practices I have used Bourdieu and Brightman's ethnographic studies, as both studies are situated within the communities' everyday environmental practices.

PIA is as an action-oriented framework that takes a significant bridging initiative between science and society. Various studies [7,9,34-37] demonstrate that there are infinite possibilities for bridging science and social science studies by shifting from the official culture [37] to a practical culture. While official culture emphasises disciplinary practice, practical culture builds upon respecting land-based knowledge, human and non-human relationships, spirituality, technology, sciences, social organization, social movements, and dynamic ecological histories [35]. To undertake this bridging initiative, we need to address the full range of SIA visions and values as metaphors, models, and formal instruments in expanding and clarifying our practice and thinking [24,35]. By bridging the works of Latour and Haraway, the practice-based SIA can build a significant network which is socially and ecologically flat and interconnected. It is neither a simple pyramid of predictable power with cybernetic control by technoscientific knowledge, nor is it relational and connectional; rather, it is laced with collective, shared power and linked to land-based emergent practice [14,34-39]. In this way, Bourdieu and Brightman's ethnographic studies provide a bridge between Foucault, Latour, and Haraway's theoretical contributions.

In practice, science and culture are not separated; they are relational, holistic, collective, transformative, observational, and flattering $[6,19,25,40]$. Connecting our knowledge with our everyday experience will allow us to question our disciplinary practice and overcome the traditional technoscientific structure [41] (p. 200). By building a practice-based understanding, we can challenge Western knowledge, which is controlled by complex sociotechnical relations. I agree with Haraway's argument that we must find another relationship to nature besides reification, possession, appropriation, and nostalgia. No longer able to sustain the fictions of being either subjects or objects, all the partners in the strong conversations that constitute nature must find a new ground for making meanings together [41] (p. 126).

\section{How to Redefine PIA?}

In redefining PIA, Foucault, Latour, and Haraway's contributions have the potential to challenge disciplinary nature/culture illusions, particularly when considering how nature is separated from 
practice. Foucault's concept of heterotopia, Latour's concept of thing, and Haraway's cyborg demonstrate how nature and culture are interconnected in practice.

\subsection{Foucault's Concept of Heterotopia}

Foucault's (1984) concept of heterotopia helps to explain how community's traditional (everyday) knowledge is alive and significant and able to break down the nature/culture, science/culture boundaries in everyday practices [41]. Foucault describes heterotopia as neither here nor there, as simultaneously physical and mental. It is the space or place in which we live, where our time and our history occur. It is a "space that claws and knows at us and is also, in itself, a heterogeneous space" [42], (p. 23). The concept of heterotopia suggests a set of relations by which a given site can be defined in everyday life. Foucault explains that our interpretation of actions or interactions is defined by a certain amount of opposition: "These are oppositions that we regard as simple givens: for example between private space and public space, between family space and social space, between cultural space and useful space, between the space of leisure and that of work" (p. 2). Foucault uses a mirror as a metaphor for duality and contradictions and the reality and the unreality of utopian thoughts. According to Foucault, a mirror is a metaphor for utopia, as the virtual image that we see reflected is not real. However, it is also heterotopia because the mirror is a real object that shapes the way we relate to our own image. As such, Foucault explains, the understanding of our actions or meanings are given to us by a set of relational practices [39-42].

\subsection{Latour's Concept of Things}

In redeveloping SIA, Latour's (2002) concept of things (both human and non-human, such as technology, computers, phones, and natural phenomena) can advance our understanding of interdisciplinary as an integral part of our existence [43]. Latour explains that "the human... cannot be grasped and saved unless that other part of itself, the share of things, is restored to it" [44], (p. 136). In our everyday practice, we are dependent on various things, such as laptops, electricity, and so on. Latour insists that, "There is no other way to define an action but by asking what other actors are modified, transformed, perturbed or created by the character that is the focus of attention" [41] (p. 122). Non-human actors—such as houses, airplanes, mobile phones, foodstuffs, plagues, or missiles—are not merely background, foundation, transparent means or passive objects of human actions; they too are capable of influencing nature/culture. Latour (2004) argues that scientific knowledge is a social construction and that we do not have a choice as to whether or not to engage with ecology [27]. He argues that the structure of scientific knowledge is a given situation where scientists are working within a created culture with its own unique sets of values and practices. According to Latour, the created culture is responsible for determining what types of knowledge are seen as real in the eyes of scientists, who in turn impose their laboratory-created knowledge on their clients. In studying nature, science cannot be separated from culture [28].

Latour's concept of things is able to break down the boundaries between science and society that occur in interdisciplinary practice and help us to redefine our methods for understanding the environment. From Latour's perspective, research can be seen as collective networks of individuals, institutions, and objects who want to win acceptance for their particular version of reality or knowledge. He advocates breaking down "two house knowledge systems" (nature and society), as these systems are set up for scientific interest [27], (p. 37). Latour's concept of things is not simply additive but is rather an initiative to bring nature and humans together. It gives importance to "knowledge, morality, and polities simultaneously" as well as to multiplicity [28], (p. 57) and is generated by actors who are interacting, sharing, and trading knowledge, and expanding their networks with one another [44-48].

\subsection{Haraway's Concept of Cyborg}

Haraway's concept of cyborg makes a significant contribution towards deconstructing the science/society paradox and reconfiguring the meaning of SIA. Haraway (1991) explains the 
relationship between science/society and nature/culture in her Cyborg Manifesto, in which natural science and feminist studies are seen as cyborgs [13], (p. 149). She argues that scientific knowledge is ideologically biased and can create misconceptions on our reality. Here I use the term "reality" as our everyday practice. Haraway's cyborg exceeds disciplinary boundaries, rejects universalism and totalising theory, all of which she contends are foundations of patriarchy. Haraway's cyborg can be seen as a combination of human and non-human (animal, machine, and more). Haraway's cyborg breaks down science/society divisions; relationships are formed from complete parts. Cyborgs are not "reverent", rather they are "need[ed] for connection" [13], (p. 151). As a postmodern feminist, Haraway fits her cyborg theory within an anti-essentialist tradition [7].

Haraway's cyborgs are metaphors that encourage the breakdown of the science/society dichotomy. Central to Haraway's theory is the image of the cyborg as "a cybernetic organism, a hybrid of machine and organism, a creature of social reality as well as a creature of fiction" (p. 149). She not only unpacks the ambiguity and irrelevance of science/society and nature/culture binaries but rather, like Latour (2004), denies that nature itself has ever existed. She argues that nature cannot pre-exist its construction and it is made of both "fiction and fact" [28], (p. 65). The cyborg is a model for the way in which identity can be reconstructed within the framework of the organic metaphor. Because they are neither technology nor nature, women nor men, nature nor culture, science nor society, body nor mind, human nor machine, one nor many, they fit into all and are not limited within these boundaries. She says:

\begin{abstract}
In the belly of the local/global monster in which I am gestating, often called the postmodern world, global technology appears to denature everything, to make everything a malleable matter of strategic decisions and mobile production and reproduction processes. Technological decontextualization is an ordinary experience for hundreds of millions if not billions of human beings, as well as other organisms. I suggest that this is not a denaturing so much as a particular production of nature [38], (p. 65-66)
\end{abstract}

Through Haraway's cyborg, PIA can be seen as an agent of deconstruction as within SIA, providing opportunities for multiplicity and contradiction. Her cyborg work is an attempt to reconfigure and allow others to reconfigure what counts as knowledge, what counts as reality (i.e., practice) in the fields of technoscience, biology, culture, and so on [13]. The potential to change, the capacity to generate: these characteristics very much suggest that a cyborg has agency. Haraway's work does not fit within social constructivism or naturalism; rather, her work is a serious interdisciplinary effort to move beyond assuming distinctions and to deal with hybrids and border zones. As she writes:

The cyborg is a matter of fiction and live experience...is struggle over life and death, but the boundary between science fiction and social reality is an optional illusion. The cyborg skips the step of original unity, of identification with nature in the Western sense [13], (p. 149-150)

Haraway's cyborg not only helps us to understand the contractions in our scientific research, but also suggests that practice has a sort of agency and is not merely a transparent tool for humans to use.

Despite Foucault, Latour, and Haraway's methodological diversity, their contributions are united by a concern to bring into conversation the natural and the social sciences in order to better understand relations between human beings and the scientific research. Crucial to the work of environmental researchers, in this regard, is the overcoming of the science-society dualism.

\title{
5. How to Do Environmental Research "from and within" Practice?
}

For reconfiguring "from and within" practice is significant for environmental research. Although Foucault, Latour, and Haraway's contributions add significant alternatives for understanding the nature/culture and science/society misconceptions in our SIA, despite their significance, they do not explain how various forms of realities (i.e., practices) coexist in their approaches. Without incorporating practice from and within, Foucault, Latour, and Haraway's alternatives may create different forms of scientific illusions [49]. Haraway's concept of cyborg takes a bold step in collaborative post-structural 
science and social science studies by breaking down the science/culture scientific dichotomy and creating alternative possibilities; however, she could not overcome Western philosophical hegemony, as she did not take into account the Indigenous worldview in understanding relationships with nature [13]. Therefore, her methodology lacks the holistic view of relationships among humans and elements. She also falls short of practical engagements with things. Practice-based IA integrates each person into a holistic worldview where everything is important and respectfully connected. In practice, nature is not a separate concept from culture, but rather mutually connected within our practice $[23,37]$. Haraway, Foucault, and Latour explore the new forms of PIA, but they do not provide enough explanation as to how SIA can be put into practice or its political significance on a technoscientific project [13,44-48]. However, I agree with Latour (2004) that both science and science studies need to be redefined [28].

For reconfiguring environmental research, practice from and within, Bourdieu (1990) and Brightman's (1993) ethnographic studies are significant [2,3]. Although Bourdieu's ethnographic study on a Kabyle community and Brightman's contributions in a Cree community do not discuss Foucault, Haraway, and Latour's worldview, they do provide a well-defined, collaborative understanding of nature in everyday practice. Therefore, adding Bourdieu and Brightman's ethnographic studies to Foucault, Latour, and Haraway may be a departure point from Western scientific nature/culture illusions [13,44-49]. Bourdieu and Brightman's ethnographic contributions are more than significant additions to collaborative SIA (Foucault, Latour, and Haraway); they are substantial in redefining nature/culture from and within practice.

\subsection{Bourdieu's Logic of Practice}

Bourdieu's (1990) study, The Logic of Practice, is the result of ethnographic fieldwork in Algeria. His practice-based work challenges our Western understanding of nature/culture [2]. His work explores kinship patterns, the social construction of domestic space, social categories of perception and classification, as well as ritualised actions and exchanges. Bourdieu's study is noteworthy for understanding collaborative approaches in practice. For example, for Bourdieu, a house is not just a building or a collection of walls. It has logical, relational meanings in everyday life: "The house is a world within a world" [2], (p. 282). He explains that, in practice, actors are relationally engaged, not simply involved in stylised, differentiated interactions. According to Bourdieu (1990), a house has different parts (such as front door, back door, south wall, west wall, roof, and floor, along with front and back windows) and all of these sections have the capacity to act and influence human actors' actions [2]. House is a relational place and able to explain different actors, both human and non-human, and the social, economic, environmental, and cultural aspects of their roles.

First, a house is a social and a cultural space. For example, the front wall on the north side of a Kabyle house is a symbol of respect and youthful brightness. The front wall is also recognised as an entry onto the community. It is situated close to the front door and windows. This wall is full of light from the front window and door, and these sources of light are recognised as a light in the darkness. By contrast, the south wall is situated in a lower part of the house without a sufficient light source. This wall is recognised as a symbol of darkness. However, the back wall is no less important than the front wall. It is a symbol of protection and a regenerative space. For example, it is a place for both animal and human intercourse and childbirth. Intercourse and childbirth sustain our relationship with our ancestors, providing a connection between humans and animals and the current generation and its ancestors. Guests are treated with honour and are invited to sit near the front wall; however, a bad person or a sick person will be seated near the back wall so that their sickness and badness can be washed away. Similarly, a newlywed couple sits at the front door in order to receive the power of fertility and lengthy stability in their lives.

Secondly, the house is a place for environmental and economic activity. The inside and outside of a house have different environmental and economic influences. For example, during summer, the door is open for light; a closed door means sickness, death, dishonour, and unhappiness. Similarly, the outside 
of the house symbolises potential and community involvement. Outside is the inspiration for working hard in the field. Sitting inside a house during the summer is a symbol of laziness and disrespect. On the other hand, a woman inside a house is a symbol of decision-making and managerial powers.

Bourdieu's theory is not simply a symbol of a collective group of actors; it displays how actors interact with each other according to everyday needs, culture, and relationships. The relational logic of everyday relationships is a significant part of the Kabyle community. For example, a man is viewed as daylight or sunlight, bringing brightness and economic stability, while a woman is compared to moonlight, symbolising protection for both humans and animals. Bourdieu says, "Woman are the foundation, man the master beam" [2], (p. 275). As a result, Bourdieu's study can be seen as a significant addition to redefine practice "from and within" in environmental research.

\subsection{Brightman's Concept of Rock}

Brightman's (1993) study of Canadian Cree Indigenous communities provides various insights into relationships between human and animals through his concept of a rock [3]. For instance, Brightman shows that in the Cree community, humans and animals occupy the same position through a rock. The rock has various meanings, such as respect, responsibility, dreams, reciprocity, regeneration, famine, hunting, and so on. For Brightman, a rock can be both human and animal. Relationships in the Cree community's daily life interactions are influenced by their culture. A rock in the Cree community becomes a tool for identifying how a person can be successful in their material life, while a bad dream can symbolise a threat. Hence, Brightman defines rock as "sources of knowledge" [3], (p. 76) and spirituality is incorporated into the Cree meaning of nature and culture.

For Brightman, science and society, nature and culture are multidimensional, more complicated than the SIA interpretation of nature. In Cree traditions, rock was the original owner of culture before humans [31]. Brightman agrees that the Cree have a nature/culture dualism similar to the Western one, but they "will not be replaced" by each other [3], (p. 42). He explains that a rock is a powerful entity in understanding Cree meanings of culture and a symbol of success, power, blessings, welfare, and selection rights. He points out that rock as relationship is beyond the nature/culture, science/society dichotomies; practice needs to see within culture, needs, and values. For him, from-and-within practice perspectives, science, and society are not separate, but rather connected as part of our responsibility for self, animal, family, and society [3,43].

\section{Discussion}

Underpinning this paper is an understanding of the potential tensions between differences in SIA and PIA in environmental research. It is therefore necessary to have a clear conceptualisation of these tensions in order to understand how interdisciplinary research manages to overcome them. As I have demonstrated from Foucault, Haraway, and Latour's collaborative contributions, a practice-based approach is able to produce new and critical accounts of environmental research, and of the knowledge underpinning it. Specifically, by "decentring" the concepts of actors, our research intension, and knowledge towards practice, PIA is from and within the community, and is able to go beyond dichotomies of science/culture, thinking/doing, technology/society, and representations/reality.

For redefining environmental research from PIA, Foucault, Latour, and Haraway's collaborative contributions can create a significant transformation in PIA. For instance, Foucault's heterotopia opens up a new way of examining historical constructions. He questions the way in which theories and knowledge are conditioned by certain historical axioms. Foucault's discourses offer different subjective positions and define who is allowed to use certain languages (for instance, ecology, biology, and environmental science). Latour $(1998,2004)$ explicitly explained conceptual ambiguities in SIA. He not only questions our ideas of nature, but also our idea of being human [27,43-47]. Like Haraway's cyborg (1991), Latour $(1998,2004)$ claims that a person cannot be understood as a free and autonomous being because of their relationships with things, natural objects, and much more than that [13,44-48]. His position therefore implies a confrontation with humanism in its singular definitive form. Latour 
argues that political ecology has nothing to do with nature as such, and political ecology has never been about nature unsullied by human hands. Instead, he says it is about infinite ties or connections that always include human participation in one form or another. Therefore, for Latour, it is not about nature, but rather the complicated relationships between things: "regulations, equipment, consumers, institutions, habits, cows and pigs" [44], (p. 229). Haraway's (1991) extraordinary contributions on cyborg helps us to understand conceptual contradiction in SIA [13]. Haraway asserts that, "Biology tells about origins, about genesis, and about nature" [13], (p. 72). Haraway's cyborgs are metaphors of the breakdown of the systems of duality. She not only deconstructs the nature/culture, science/society dichotomy, she also re-envisions reality from her cyborg perspective. Haraway's meanings of cyborgs are neither technology nor nature, woman nor man, human nor machine, one nor many; instead they fit into both with multiple qualities. In A Cyborg Manifesto, Haraway develops the figure of the cyborg in order to offer an alternative means of discussing nature in a postmodern technological age. Haraway's cyborg exceeds the boundaries of both science and social science studies, rejects universalism and totalising theory, all of which she contends are foundations of patriarchy. As a hybrid (animal-human) machine, the cyborg nullifies organic holism and the Western myth of an origin story. As a postmodern feminist, Haraway fits her cyborg theory into an anti-essentialist tradition $[13,41]$.

Foucault, Latour, and Haraway together have enormous potential. Their collective contributions question our basic assumptions of the science and society dichotomy and challenge the scientific model. They connect various non-human elements—such as animals, plants, parasites, and other organisms-with things, but their relationships and spirituality are not addressed from a holistic understanding of nature and culture. Moreover, Latour admits that the networks of relationships do not cover all that is palpable. Indeed, there is much to the world that simply is unknown. "The world is not a solid continent of facts speckled by a few islands of calibrated and stabilized forms" [26], (p. 245). Haraway's perspective bears a remarkable resemblance to many post-structuralist ideas; however, since she considers human, animal, and nature as Western phenomena, she fails to understand an Indigenous holistic approach, misunderstanding how to see and communicate with things and how to find the meaning stemming from Indigenous worldviews. According to Haraway, technology or technoscience is part of human and animal relationships, and this technoscience creates dependency; it is an illusion. I agree that technoscientific structure undermines things, human, animals, rocks, and spirituality $[13,41]$, but her ontology does not have the power to change our idea of what it means to be things.

Although Foucault, Latour, and Haraway's concepts (heterotopia, things, and cyborg) are helpful to unpack the conceptual contradictions in SIA, their phenomenal works do not explicitly lead us to explore how to incorporate community's practice into science research as fluid, live, and effective ways. Alone, Foucault's concept of Heterotopia does not answer the question of which forces nature is connected to in today's world. It is not possible for Foucauldian knowledge to describe the preconditions for technoscientific culture, because it is conditional and restricted and is always speaking from within [27]. Therefore, Foucault describes only those discourses and practices that have ceased to be our own. Latour's concept of things can be lined up with Haraway's concept of cyborgs in overcoming Foucault's limitations [28]. Latour adds a multiplicity of elements, pointing out that knowledge and thought should not be seen as simply mental activity; rather, they are the coming together of heterogeneous human and non-human elements [28].

For Bourdieu and Brightman, ethnographic examples are affiliated with various creatures, gods, and spirituality. These affinities have enough potential to transgress SIA theoretical phenomenology; everyday practice is also able to create collaborative meanings for things. Bourdieu and Brightman's practice-based ethnographical studies in conjunction with Foucault, Haraway, and Latour not only enlarge our various ways of understanding PIA but also help us to move beyond technoscientific SIA illusions. Haraway's cyborgs resemble humans, as they live in hierarchies and are not apart from living organisms and machines, whereas Brightman shows that the Cree paradigm denies hierarchies among such things as human and animal relationships. We must instead conceive a system of collaborative 
engagement. For Brightman, local knowledge, relationships, spirituality, and humans are not in opposition to the natural world. It is what unites them, despite all their differences. Foucault, Latour, and Haraway open an interdisciplinary door by saying that "All readings are also mis-readings, re-readings, partial readings, imposed readings and imagined readings of a text that is originally and finally simply never there" [13], (p. 124).

Within a collaborative and fluid sense of environmental research in PIA, processes and interactions are thus the results of interpretation, improvisation, and performance, and this is done through bodily movements, discursive and emotional expressions, and things and artefacts "on the stage" [1,50]. The interaction between the people, their practice, science, and policy-makers is crucial. Hence, environmental research in PIA has consequences that are inevitably situational, multidimensional, fluid, and therefore unpredictable. Logic of PIA offers a more realistic model for understanding human behaviour and environmental change [2]. By adding practice to the interdisciplinary process already in progress, our job may be to discuss, critique, and discover.

\section{Conclusions}

Issues of environmental research are too complex and/or insufficient to be addressed only by the science research $[1,9,10]$. Individuals and communities are affected only by science-based research and therefore struggle to find solutions. In this paper, I suggest that environmental research is a community-engaged, interdisciplinary, and integrated approach; can connect together the social and cultural with technological and scientific fields of practice; it can provide a setting for creative investigation and response. The PIA as a process and strategy for environmental research has potential to promote collectivity and community actions, and centralise the task for community members to understand the contradictions of the dominant ideology in the environmental research [1]. We, as environmental researchers and educators, need to reconfigure the meanings of practice from and within community. From and within-based PIA has the ability to create a process to develop critical consciousness and encourage communities (including scholars and community alike) to recognise how local issues are linked to scientific research, and partake in social action around multiple environmental issues. These forms of PIA are able to focus on the development of boundary-crossing skills and integrated knowledge-building, with the potential to transform community interaction with the environment. Environmental research in PIA is focused on the complexity of environmental issues, providing learners access to diverse methodologies for assessing environmental decisions.

This paper has broadly identified the importance of our practice-based approach in environmental research. It suggests that it is essential to fundamentally rethink the environment-humanity relationship. To characterise the environmental research in PIA through human interaction, culture, institutions, and societies - indeed, the meaning of being human-is truly another and major challenge for the interdisciplinary scholars, educators, practitioner, and policy communities. For us, as environmental researchers and educators, it is of utmost importance that we identify the ideas that environmental life is fundamentally connected to our cultural values: they cannot be separated from our practice. Post-structuralist Foucault, Haraway, and Latour scholarships have identified why using only SIA is challenging, and have contributed to our understanding of who we are as educators and researchers. Juxtaposing these ideas will ultimately lead to significant new forms of environmental research $[11,38,49-54]$. This paper anticipates that this new form of PIA will have an impact on future environmental research and education by examining how we as researchers interact with a community's practices, responses, and needs within an academic framework.

Conflicts of Interest: The author declare no conflict of interest.

\section{References}

1. Reckwitz, A. Toward a theory of social practices: A development in culturalist theorizing. Eur. J. Soc. Theory 2002, 5, 243-263. [CrossRef] 
2. Bourdieu, P. The Logic of Practice, (Trans. R. Nice); Stanford University Press: Stanford, CA, USA, 1990.

3. Brightman, R.A. Grateful Prey: Rock Cree Human-Animal Relationships; University of California Press: Berkeley, CA, USA, 1993.

4. Johannes, R.E. The case for data-less marine resource management: Examples from tropical nearshore finfisheries. Trends Ecol. Evol. (Amst.) 1998, 13, 243-246. [CrossRef]

5. Escobar, A. Territories of Difference: Place, Movements, Life, Redes; Duke University Press: London, UK, 2008.

6. Datta, R. How to practice posthumanism in environmental learning: Experiences with North American and South Asian Indigenous Communities? IAFOR J. Educ. 2016, 4, 52-67.

7. Jump, U.; Ludwig, D.; Mangel, M.; Haddad, B. Ecology, conservation, and public policy. Annu. Rev. Ecol. Syst. 2001, 32, 481-571.

8. Palsson, G.; Szerszynski, B.; Sörlin, S.; Marks, J.; Avril, B.; Crumley, C.; Hackmann, H.; Holm, P.; Ingram, P.; Kirman, A.; et al. Reconceptualizing the "anthropos" in the Anthropocene: Integrating the social sciences and humanities in global environmental change research. Environ. Sci. Policy 2013, 28, 3-13. [CrossRef]

9. Escobar, A. After nature: Steps to an anti-essentialist political ecology. Curr. Anthropol. 1999, 40, 1-30. [CrossRef]

10. Latour, B. Why has critique run out of steam? From matters of fact to matters of concern. Crit. Inq. 2004, 30, 225-248. [CrossRef]

11. Jones, C. Interdisciplinary approach-Advantages, disadvantages, and the future benefits of interdisciplinary studies. ESSAI 2010, 7, 26.

12. Escobar, A. Beyond the search for a paradigm? Post-development and beyond. Development 2000, 43, 11-14.

13. Haraway, D. Simians, Cyborgs, and Women: The Reinvention of Nature; Routledge: New York, NY, USA, 1991.

14. Kuhn, T.S. The Essential Tension: Tradition and Innovation in Scientific Research. In Scientific Creativity: Its Recognition and Development; Taylor, C.W., Barron, F., Eds.; Wiley: New York, NY, USA, 1959; pp. 341-354.

15. Sievanen, L.; Campbell, L.M.; Leslie, H.M. Challenges to interdisciplinary research in ecosystem-based management. Conserv. Biol. 2012, 26, 315-323. [CrossRef] [PubMed]

16. Stock, P.; Burton, R.J.F. Defining terms for integrated (multi-inter-trans-disciplinary) sustainability research. Sustainability 2011, 3, 1090-1113. [CrossRef]

17. Wainwright, J. Climate change, capitalism, and the challenge of transdisciplinarity. Ann. Assoc. Am. Geogr. 2010, 100, 983-991. [CrossRef]

18. Brunner, R.D.; Willard, A.R. Professional insecurities: A guide to understanding and career management. Policy Sci. 2003, 36, 3-36. [CrossRef]

19. Datta, R. A relational theoretical framework and meanings of land, nature, and sustainability for research with Indigenous communities. Local Environ. Int. J. Justice Sustain. 2015, 20, 102-114. [CrossRef]

20. Datta, R.; Khyang, U.N.; Khyang, H.K.P.; Kheyang, H.A.P.; Khyang, M.C.; Chapola, J. Understanding Indigenous sustainability: A community-based participatory experience. Rev. Bras. Pesqui. Educ. Ciênc. 2014, 14, 99-108.

21. Vince, A.; Datta, R.; Dyck, S.; Kayira, J.; McVittie, J. Meanings and implications of culture in sustainability education research. J. Environ. Educ. 2016, 47, 1-18.

22. Giddens, A. The Constitution of Society. Outline of the Theory of Structuration; Polity Press: Cambridge, MA, USA, 1984.

23. Wilson, S. Research Is Ceremony: Indigenous Research Methods; Fernwood Publications: Halifax, NS, Canada, 2008.

24. Schmitz, C.L.; Stinson, C.H.; James, C.D. Community and environmental sustainability: Collaboration and interdisciplinary education. Crit. Soc. Work 2010, 11, 83-100.

25. Law, J. Enacting Management Cultures: A Note from STS. Available online: www.lancs.ac.uk/fass/ sociology/papers/law-enactingmanagementcultures (accessed on 5 March 2017).

26. Law, J. Objects and spaces. Theory Cult. Soc. 2002, 19, 91-105. [CrossRef]

27. Foucault, M. Archaeology of Knowledge, Sheridan-Smith AM (Trans); Routledge: London, UK, 2004.

28. Latour, B. Polities of Nature: How to Bring the Sciences into Democracy; Porter, C., Ed.; Harvard University Press: London, UK, 2004.

29. Whatmore, S. Introduction. In Hybrid Geographies: Natures, Cultures, Spaces; Whatmore, S., Ed.; Routledge: London, UK, 2002; pp. 1-9. 
30. Spelt, E.J.H.; Biemans, H.J.A.; Tobi, H.; Luning, P.A.; Mulder, M. Teaching and learning in interdisciplinary higher education: A systemic review. Educ. Psychol. Rev. 2009, 21, 365-378. [CrossRef]

31. Williams, A.; Holden, B.; Krebs, P.; Muhaiarine, N.; Waygood, K.; Randall, J.; Spence, C. Knowledge translation strategies in a community-university partnership: Examining local Quality of Life (QoL). Soc. Indic. Res. 2008, 85, 111. [CrossRef]

32. Nadasdy, P. The politics of TEK: Power and the "integration" of knowledge. Arct. Anthropol. 1999, 36, 1-18.

33. Escobar, A. Latin America at a crossroads. Cult. Stud. 2010, 24, 1-65. [CrossRef]

34. Little Bear, L. Native Science and Western Science: Possibilities for a Powerful Collaboration. Available online: https: / /www.youtube.com/watch?v=ycQtQZ9y3lc (accessed on 9 May 2009).

35. Whatmore, S. Materialist returns: Practising culture geography in and for a more-than-human world. Cult. Geogr. 2006, 13, 600-609. [CrossRef]

36. Whatmore, S. Practicing more-than-Human Geographies: Thinking with/through materials. Available online: https:/ / www.youtube.com/watch?v=FVxfHV4Vl6Y (accessed on 15 January 2013).

37. Escobar, A. Constructing nature: Elements for a post-structural political ecology. Pergamon 1996, 28, 325-343.

38. Haraway, D. Science in Action: How to Follow Scientists and Engineers through Society; Harvard University Press: Cambridge, MA, USA, 1987.

39. Meyers, R. Environmental learning: Reflections on practice, research and theory. Environ. Educ. Res. 2006, 12, 459-470. [CrossRef]

40. Datta, R. Rethinking Environmental Science Education from Indigenous Knowledge Perspectives: An experience with a Dene First Nation community. Environ. Educ. Res. 2016. [CrossRef]

41. Haraway, D. The Haraway Reader; Routledge: New York, NY, USA, 2004.

42. Foucault, M. What Is Enlightenment? In The Foucault Reader; Rabinow, P., Ed.; Pantheon: New York, NY, USA, 1984; pp. 32-50.

43. Latour, B. Morality and technology: The end of means. Theory Cult. Soc. 2002, 19, 247-260. [CrossRef]

44. Latour, B. We Have Never Been Modern (Catherine Porter, Trans.); Harvard University Press: Cambridge, MA, USA, 1993.

45. Latour, B.; Hermant, E. Paris: Invisible City, Carey-Libbrecht L (Trans). Available online: http:/ / www.brunolatour.fr/virtual/PARIS-INVISIBLE-GB.pdf (accessed on 5 March 2017).

46. Latour, B. Pandora's Hope: Essays on the Reality of Science Studies; Harvard University Press: Cambridge, MA, USA, 1999.

47. Latour, B. Technology is Society Made Durable. In Sociology of Monsters. Essays on Power, Technology and Domination; Law, J., Ed.; Routledge: London, UK, 1991; pp. 103-131.

48. Latour, B. To Modernize or to Ecologize, That Is the Question. In Remaking Reality: Nature at the Millenium; Castree, N., Braun, B., Eds.; Routledge: New York, NY, USA, 1998; pp. 221-242.

49. Szostak, R. How and why to teach interdisciplinary research practice. J. Res. Pract. 2007, 3, Article M17.

50. Brightman, R.A. Nature and Culture in the Bush: A Nature/Culture Metalanguage and Rock Cree Parallels. In Nature of Spirits in Aboriginal Cosmologies; Laugrand, F., Oosten, J., Eds.; Université de Laval: Québec, QC, Canada, 2007; pp. 3-29.

51. Eller, J.D. Cultural Anthropology: Global Forces, Local Lives; Routledge: London, UK, 2016.

52. Gaboury, I.; Bujold, M.; Boon, H.; Moher, D. Interprofessional collaboration within Canadian integrative healthcare clinics: Key components. Soc. Sci. Med. 2009, 69, 707-715. [CrossRef] [PubMed]

53. Tuck, E.; McKenzie, M. Place in Research: Theory, Methodology, and Methods; Routledge: New York, NY, USA, 2016.

54. Foucault, M. The Order of Things: An Archaeology of the Human Sciences; Routledge: London, UK, 2003.

(c) 2017 by the author. Licensee MDPI, Basel, Switzerland. This article is an open access article distributed under the terms and conditions of the Creative Commons Attribution (CC BY) license (http:/ / creativecommons.org/licenses/by/4.0/). 